\title{
Evaluation of the Scoring Systems to Differentiate between Benign and Malignant Adnexal Masses in a Tertiary Care Center, Pune
}

Shilpa Nitin Chaudhari, Poorva Niteen Deshpande, Priyanka Rohit Gupta, Tanvi Rajeev Warty, Devika Bharat Bhikane

\begin{abstract}
Objective: The aim of this study was to evaluate the scoring systems to differentiate between benign and malignant adnexal masses.

Methods: It is a prospective study carried on 60 women at a tertiary care center. Transabdominal ultrasonography and color Doppler was done and women were followed till resolution of symptoms. Gold standard for diagnosis of adenexal masses was histopathological examination of specimen or fluid cytology.

Results: Efficacy of Sassone scoring system for diagnosing malignant tumors sensitivity $75 \%$, specificity $90.91 \%$, positive predictive value $75 \%$, negative predictive value $90.91 \%$ and an accuracy of $86.67 \%$. Efficacy of De Priest scoring system sensitivity $66.67 \%$, specificity $100 \%$, positive predictive value $100 \%$, negative predictive value $92.31 \%$ and an accuracy of $93.33 \%$. Efficacy of Ferrazzi scoring system sensitivity $75 \%$, specificity $100 \%$, positive predictive value $100 \%$, negative predictive value $91.67 \%$, and an accuracy of $93.33 \%$. Efficacy of alcazar scoring system sensitivity $100 \%$, specificity $100 \%$, Positive predictive value $100 \%$, negative predictive value $100 \%$, and an accuracy of $100 \%$.
\end{abstract}

Conclusion: Alcazar scoring system was found to be more sensitive and specific than other available scoring systems.

Keywords: Adnexal mass, Alcazar system, Color Doppler, Scoring systems

How to cite this article: Chaudhari SN, Deshpande PN, Gupta PR, Warty TR, Bhikane DB. Evaluation of the Scoring Systems to Differentiate between Benign and Malignant Adnexal Masses in a Tertiary Care Center, Pune. J South Asian Feder Obst Gynae 2013;5(3):135-138.

Source of support: Nil

Conflict of interest: None

\section{INTRODUCTION}

Adnexal mass is an enlarged structure in the uterine adnexa (ovary, tubes or broad ligament) which can either be palpated on a bimanual pelvic examination or visualized using sonongraphic imaging. Pelvic pathology can present with several distressing symptoms and a varied clinical presentation which include infertility, pain in abdomen, menstrual disorders, backache, dyspareunia and many times there are no symptoms at all. ${ }^{1}$ Adnexal mass usually represents a specific pelvic pathology at specific age (like malignant tumors being more common in prepubescent and postmenopausal women) and sometimes may create difficulty as far as diagnosis and management is concerned. ${ }^{1}$
One of the first sonographic descriptions of ovary was given by Kratochwil et $\mathrm{al}^{2}$ in 1972 . After describing the normal sonographic appearances of the ovary, they also discussed the possibility of improved imaging with the transvaginal approach). In the mid 1970s, many authors described the sonographic features of pelvic masses and those parameters that could be used to differentiate benign from malignant lesions. Various scoring systems have been used since then to differentiate preoperatively, benign from maliganat ovarian masses. Among the sonological scoring systems are Alcazar, ${ }^{3}$ Sassone, ${ }^{4}$ De Priest,${ }^{5}$ Ferrazi ${ }^{6}$ to name a few. Any palpable mass in a postmenopausal woman has been considered abnormal, the "palpable postmenopausal ovary syndrome" 7 Adnexal masses presents diagnostic difficulties, partly because benign adnexal masses are more common than malignant ones. Determination of a degree of suspicion for malignancy is very important and is based much on sonographic appearance. ${ }^{8}$ Since ovarian cancer presents in a later stage and carries the worse prognosis among gynecological cancers, it is extremely important for every gynecologist to differentiate between a benign and malignant adnexal mass. Use of color Doppler in conjunction with ultrasonography improves the sensitivity of detecting an adnexal masses.

\section{METHODOLOGY}

The present prospective study of 60 cases was conducted at Padmashree Dr DY Patil Medical College, Hospital and Research Centre, Pimpri, Pune from July 2010 to August 2012 in women of reproductive (20 to 40 ) and perimenopausal (40 to 50) age group. Fifteen women were assigned to each scoring system.

On admission, a detailed history was taken and complete examination was done. All patients were subjected to transabdominal ultrasonography and color Doppler examination with the use of GE machine. They were then followed up till resolution of signs or symptoms with conservative management or surgical intervention. The gold standard for the diagnosis was histopathological examination of specimen obtained from laparotomy or cytology of ascitic fluid.

\section{Scoring Systems}

The sonographic parameters of the scoring system included thick papillary projections and solid areas. The color Doppler parameters included blood flow (present or absent), blood flow location (central or peripheral), resistance index, peak systolic velocity (PSV) and velocimetry (high velocity/low resistance). 
CA-125 was sent in all cases where malignancy was suspected or ultrasonography score was high.

RMI I (Risk of malignancy index) score was calculated for all cases using the formula:

$\mathrm{RMI}=$ menopausal status $(\mathrm{M}) \times$ ultrasound score $(\mathrm{US}) \times$ serum CA-125.

The results were analyzed using the following statistical tests evaluation of the scoring systems to differentiate between benign and malignant adnexal masses in a tertiary care center.

- Sensitivity, specificity, negative predictive value, positive predictive value.

- Proportionality $-\mathrm{Z}$ test.

\section{RESULTS (TABLES 1 TO 5)}

Out of 60 patients laparotomy was done for 37 cases. Criteria for laparotomy were: sonographically diagnosed large tumors, malignant tumors, no response to drugs, broad ligament myomas. Laparotomy was done in 37 cases to reach final diagnosis. Majority of them were benign ovarian tumors (22 cases). All the operable malignant adnexal masses underwent laparotomy. ${ }^{12}$ Final diagnosis was achieved by Histopathological examination of the specimen after laparotomy, cytology of fluid from the mass or ascitic fluid. Majority of them were benign ovarian tumors $55 \%$.

Efficacy of Sassone scoring system for diagnosing malignant tumors sensitivity $75 \%$, specificity $90.91 \%$, positive

\begin{tabular}{clcc}
\multicolumn{4}{c}{ Table 1: Diagnosis after transabdominal USG } \\
\hline Sr. no. & \multicolumn{1}{c}{ Diagnosis } & $\begin{array}{c}\text { USG } \\
\text { diagnosis }\end{array}$ & $\begin{array}{c}\text { Final } \\
\text { diagnosis }\end{array}$ \\
\hline 1 & Benign ovarian tumors & 34 & 33 \\
2 & Malignant ovarian tumors & 08 & 14 \\
3 & Polycystic ovarian disease & 06 & 06 \\
4 & Hydrosalpinx & 07 & 04 \\
5 & Tubo-ovarian mass & 04 & 02 \\
6 & Broad ligament myoma & 01 & 01 \\
\hline \multicolumn{2}{c}{ Total } & 60 & 60 \\
\hline
\end{tabular}

\begin{tabular}{clcr}
\multicolumn{4}{c}{ Table 2: Laparotomy diagnosis } \\
\hline Sr. no. & Diagnosis & No. of cases & $\%$ \\
& & & \\
\hline 1 & Benign ovarian tumors & 22 & 59 \\
2 & Malignant ovarian tumors & 12 & 32 \\
3 & Tubo-ovarian mass & 02 & 5 \\
4 & Broad ligament myoma & 01 & 4 \\
\hline & Total & 37 & 100 \\
\hline
\end{tabular}

\begin{tabular}{clcc}
\hline \multicolumn{4}{c}{ Table 3: Final diagnosis } \\
\hline Sr. & Diagnosis & No. of cases & $\%$ \\
no. & & 33 & 55 \\
\hline 1 & Benign ovarian tumors & 14 & 23 \\
2 & Malignant ovarian tumors & 06 & 10 \\
3 & Polycystic ovarian disease & 04 & 6.7 \\
4 & Hydrosalpinx & 02 & 3.6 \\
5 & Tubo-ovarian mass & 01 & 1.7 \\
6 & Broad ligament myoma & 60 & 100 \\
\hline
\end{tabular}

predictive value $75 \%$, negative predictive value $90.91 \%$, and an accuracy of $86.67 \%$. Efficacy of DePriest scoring system sensitivity $66.67 \%$, specificity $100 \%$, positive predictive value $100 \%$, negative predictive value $92.31 \%$, and an accuracy of $93.33 \%$. Efficacy of Ferrazzi scoring system sensitivity $75 \%$, specificity $100 \%$, positive predictive value $100 \%$, negative predictive value $91.67 \%$ and an accuracy of $93.33 \%$. Efficacy of Alcazar scoring system sensitivity $100 \%$, specificity $100 \%$, positive predictive value $100 \%$, negative predictive value $100 \%$ and an accuracy of $100 \%$.

\section{DISCUSSION}

Sassone et $\mathrm{al}^{4}$ devised a scoring system using traditional gray scale transvaginal ultrasonography to characterize ovarian lesion. The scoring system was based on determining the wall thickness, inner wall structure, characteristics of septa and echogenecity of lesion. DePriest et $\mathrm{al}^{5}$ developed a scoring system based on volume, cyst wall structure, and septal structure of adnexal mass assessed by sonography. Ferrazzi et $\mathrm{al}^{6}$ developed a scoring system based on wall thickness, septa, vegetations and echogenecity. Color Doppler parameters were not included in their scoring systems by Sassone, DePriest and Ferrazzi. After introduction of color Doppler, RI and PSV were not used as independent predictors of malignancy because considerable overlapping was found between benign and malignant tumors in spite of statistical difference. ${ }^{3}$ To overcome this limitation, in the scoring system of Alcazar et $\mathrm{al}^{3}$ tumors were classified in four velocimetric categories according to the best RI and PSV cut off values. Only those variables were used which were independent predictors of malignancy in multivariate logistic regression analysis. This scoring system may yield a total score of 0 to 12 . Score of 6 or more was taken as malignant.

Using Sassone scoring system and taking $>8$ as cut off value for malignancy, we found that out of 15 cases, 11 , i.e. $73.3 \%$ had a score of $<8$ and out of these 11 cases, all were benign on histopathology. Only 1 case with a score of $>8$ was benign. In this patient, tumor was cystic with no solid areas but had

\begin{tabular}{llcccc}
\multicolumn{5}{|c}{ Table 4: Comparison of efficacy of Alcazar scoring system } \\
as with other 3 scoring systems \\
\hline $\begin{array}{l}\text { Sr } \\
\text { no. }\end{array}$ & Scoring system utility & Sassone & DePriest & Ferrazzi & Alcazar \\
\hline 1 & Sensitivity & 75 & 66.67 & 75 & 100 \\
2 & Specificity & 90.91 & 100 & 100 & 100 \\
3 & Positive predictive value & 75 & 100 & 100 & 100 \\
4 & Negative predictive value & 90.91 & 92.31 & 91.67 & 100 \\
\hline
\end{tabular}

\begin{tabular}{lccc}
$\begin{array}{l}\text { Table 5: Univariate analysis of variables used in assessment of } \\
\text { adnexal mass by Alcazar system }\end{array}$ \\
\cline { 1 - 3 } $\begin{array}{l}\text { Diagnosis based on histopathology } \\
\text { Malignant } \\
(n=14)\end{array}$ & $\begin{array}{c}\text { Benign } \\
(n=46)\end{array}$ \\
\cline { 2 - 3 } & 8 & 4 & $<0.05$ \\
Thick papillary projection & 5 & 2 & $<0.05$ \\
Solid element & 7 & 2 & $<0.05$ \\
Central flow & 1 & 2 & $>0.05$ \\
Velocimetry & 5 & &
\end{tabular}


irregular inner wall structure with wall thickness $<3 \mathrm{~mm}$ and septae $>3.5 \mathrm{~mm}$. Her final diagnosis came out to be tubo-ovarian mass. Only one case with a score of $<8$ was malignant. In this patient the cyst wall structure was smooth with walls $<3 \mathrm{~mm}$ in thickness, no septae and it was sonoluscent. Her final diagnosis was serous cystadenocarcinoma.

Using DePriest scoring system and taking $>6$ as cut off value for malignancy, we found that out of 15 cases, 13 , i.e. $86.6 \%$ had a score of $<6$ and out of these 13 cases, 12 were benign on histopathology. Only one case with a score of $<6$ was malignant. She had a smooth wall structure which was $<3 \mathrm{~mm}$ and a tumor volume of 50 to $200 \mathrm{cc}$. ${ }^{3} \mathrm{Her}$ final diagnosis was serous cystadenocarcinoma.

Using the Ferrazzi scoring system and taking $>8$ as cut off value for malignancy, we found out of 15 cases, 11 , i.e. $73.3 \%$ had a score of $<8$ and out of the 11 cases all were benign on histopathology. Only one case with a score of $<8$ was malignant. She had an irregular solid wall, no septa and it was sonoluscent. Her final diagnosis was adenocarcinoma of ovary.

The scoring system by Alcazar gave better results because of the use of color Doppler measurements. ${ }^{3}$ The use of color Doppler decreased false-positive results. The efficacy of a morphologic scoring system alone was hampered by overlap between malignant and benign appearing masses.

Following points should be considered while using Alcazar scoring system. Utrasonographic and color Doppler technique is highly operator dependent leading to high interobserver variation. Also the flow within the tumor varies greatly. So the whole mass should be adequately scanned by only an expert sonologist.

In our study using Alcazar scoring system, it was found that thick papillary projections $(\geq 3 \mathrm{~mm})$ was statistically significant $(\mathrm{p}<0.05)$ in the differentiation of benign from malignant ovarian mass. Singh et $\mathrm{al}^{9}$ in their study found on scoring systems to differentiate between benign and malignant masses found papillary thickness $\geq 3 \mathrm{~mm}$ was found to be significant $(\mathrm{p}<0.02)$. Alcazar et $\mathrm{al}^{3}$ in their study showed that thick papillary projections were significant $(\mathrm{p}<0.0001)$.

In our study using Alcazar scoring system, it was found that solid component was statistically significant $(p<0.05)$ in the differentiation of benign from malignant ovarian mass. Brown et $\mathrm{al}^{10}$ found that a solid component is the most statistically significant predictor of a malignant ovarian mass $(\mathrm{p}<0.001)$. Schelling et $\mathrm{al}^{11}$ found papillary structure in cysts had a sensitivity of $67 \%$ and a specificity of $81 \%$, while detection of solid area had sensitivity of $95 \%$ and specificity of $68 \%$ for the detection of malignancy.

Also, central flow was statistically significant $(p<0.05)$ in the differentiation of benign from malignant ovarian mass. Carter et $\mathrm{al}^{12}$ in their study concluded intratumor color flow to be more common in malignant tumors than benign ones. It was statistically significant $(\mathrm{p}<0.001)$.

Singh et $\mathrm{al}^{9}$ showed that presence of central vascularization was significant $(\mathrm{p}<0.001)$. Merce et $\mathrm{al}^{13}$ in their study on 213 women using B-mode transvaginal ultrasonography color Doppler characteristics concluded that vascularization was seen in $100 \%$ of the malignancies, in central areas, mostly $(90 \%$ in his study) and by stark contrast, only $52 \%$ of the benign tumors showed vascularity, mostly in peripheral areas $(98 \%$ in his study). Alcazar et $\mathrm{al}^{3}$ concluded central blood flow was found to be a predictor of malignancy $(\mathrm{p}<0.0001)$. Brown et al found that central flow has a stronger association with malignancy than does solely peripheral flow, which has a stronger association than no flow.

In our study, velocimetry (high velocity/low resistance) was not of statistical significance $(p>0.05)$ consistent with Kurtz et $\mathrm{al}^{14}$ who in their study found the thresholds for malignancy were a pulsatility index of $<1.0$ and a resistive index of $>0.4$. Szpurek et al ${ }^{15}$ found statistically significant differences in PSV (peak systolic velocity) median values when considering histological grade $(p=0.01)$ and also when considering clinical stage of disease according to International Federation of Gynecology and Obstetrics (FIGO) $(\mathrm{p}=0.001)$. However, they found no significant difference in the median values of the blood flow parameters of PI and RI.

The false-positive result in the scoring systems of Sassone and DePriest and Ferrazzi were basically due to high scoring of benign lesions like teratoma, endometrioma and ovarian fibroma.

Alcazar scoring system was tested with three scoring systems and found the best diagnostic performance was achieved by Alcazar scoring system with $100 \%$ sensitivity, $100 \%$ specificity and the highest accuracy, which was significantly higher than for the scoring systems of Sassone et $\mathrm{al}^{4}{ }^{4}$ DePriest et $\mathrm{al}^{5}$ and Ferrazi et al. ${ }^{6}$

\section{CONCLUSION}

Use of transabdominal and transvaginal gives a better assessment of larger masses and extraovarian disease. Use of color Doppler in conjunction with ultrasonography improves the sensitivity of detecting an adnexal masses. CA-125 assay was not shown to be useful because of its poor specificity. However, values more than $200 \mathrm{IU} / \mathrm{ml}$ have a high prediction with malignancies.

The use of color Doppler decreased the false-negative results. Presence of central vascularization $(p=0.000)$ and high velocity/low resistance $(p=0.000)$ were most consistently associated with malignancy. Addition of color Doppler increases the specificity and diagnostic performance of Alcazar scoring system. Alcazar scoring system was found to be more sensitive and specific than other available scoring systems. However, considering the small sample size of the present study further studies need to be conducted for a conclusive proof.

\section{REFERENCES}

1. Drake J. Diagnosis and management of adnexal mass. Am Fam Physician 1998;57(10):2471-2476.

2. Kratochwil A, Urban G, Friedrich A. Ultrasonic tomography of the ovaries. Ann Chin Gynecol Fenn 1972;61:211-214.

3. Alcazar JL, Mercee LT, Laparte C, Juardo M, Lopez-Gracia. A new scoring system to differentiate benign from malignant adnexal mass. Am J Obs Gynecol 2003;188:685-692. 
4. Sassone AM, Timor-Trisch IE, Artner A, Westhoff C, Warren WB. Transvaginal sonographic characterization of ovarian disease: evaluation of a new scoring system to predict malignancy. Obstet Gynecol 1991;78:70-76.

5. De Priest PD, Shenson D, Fried A, Hunter JE, Andrew SJ, Gallion HH, Pavlik EJ, Kryscio RJ, Van Nagell JR Jr. A morphologic index based on sonographic findings in ovarian cancer. Gynecol Oncol 1993 Oct;51(1):7-11.

6. Ferrazi E, Zanetta G, Dordoni D, Berlanda N, Mezzopane R, Lissoni AA. Transvaginal ultrasonographic characterization of ovarian masses: comparison of five scoring systems in multicentre study. Ultrasound Obstet Gynecol 1997 Sep;10: 192-197.

7. Barber HR, Graber EA. The syndrome PMPO (postmenopausal palpable ovary) CA Cancer J Clin 1972 Nov-Dec;22(6): 357-359.

8. Myers ER, Bastian LA, Havrilesky LJ, Kulasingam SL, Terplan MS, Cline KE, Gray RN, McCrory DC. Management of Adnexal Mass. Evid Rep/Technol Assess (Full Rep) 2006 Feb;130: 1-145.

9. Singh U, Kohli N, Nisha, Ekta. Evaluation of a new scoring system to differentiate between benign and malignant adnexal mass. J Obstet Gynecol India 2006 Mar-Apr;56:162-165.

10. Brown DL, Doubilet PM, Miller FH, Fates MC, Laing FC, DiSalvo DN, Benson CB, Lerner MH. Benign and malignant ovarian masses: selection of the most discriminating gray-scale and Doppler sonographic features. Radiology 1998 Jul;208(1): 103-110.

11. Schelling M, Braun M, Kuhn W, Bogner G, Gruber R, Gnirs J. Combined Transvaginal B-mode and color Doppler sonography for differential diagnosis of ovarian tumors: results of a multivariate logistic regression analysis. Gynecol Oncol 2000 Apr;77(1):78-86.

12. Kriplani A, Ahuja R, Chowdhary VP, Takkar D. Large ovarian hematoma in a case of immune thrombocytopenic purpura presenting as an ovarian cyst. J Obstet Gynecol India 1996 Oct;46(5):713-714.

13. Mercee LT, Caballero RA, Barco MJ, Bau S, Lopez G. B-mode, utero-ovarian and intratumoral transvaginal colour Doppler ultrasonography for differential diagnosis of ovarian tumors. Eur J Obstet Gynecol Reprod Biol 1998 Jan;76(1):97-107.

14. Kurjak A, Kupesic S. Three-dimensional ultrasound and power Doppler is assessment of uterine and ovarian angiogenesis: a prospective study. Croat Med J 1999 Sep;40(3):413-420.

15. Folkman J, Merler E, Abernathy C, Williams G. Isolation of a tumor factor responsible for angiogenesis. J Exp Med 1971 Feb;133(2):275-288.

\section{ABOUT THE AUTHORS}

\section{Shilpa Nitin Chaudhari}

Professor, Department of Obstetrics and Gynecology, Padmashree Dr DY Patil Medical College, Hospital and Research Centre (Dr DY Patil Vidyapeeth), Pune, Maharashtra, India

\section{Poorva Niteen Deshpande (Corresponding Author)}

Resident, Department of Obstetrics and Gynecology, Padmashree Dr DY Patil Medical College, Hospital and Research Centre (Dr DY Patil Vidyapeeth), Pune, Maharashtra, India, Phone: +91-9422325740 e-mail: d.poorva@yahoo.com

\section{Priyanka Rohit Gupta}

Lecturer, Department of Obstetrics and Gynecology, Padmashree Dr DY Patil Medical College, Hospital and Research Centre (Dr DY Patil Vidyapeeth), Pune, Maharashtra, India

\section{Tanvi Rajeev Warty}

Resident, Department of Obstetrics and Gynecology, Padmashree Dr DY Patil Medical College, Hospital and Research Centre (Dr DY Patil Vidyapeeth), Pune, Maharashtra, India

\section{Devika Bharat Bhikane}

Resident, Department of Obstetrics and Gynecology, Padmashree Dr DY Patil Medical College, Hospital and Research Centre (Dr DY Patil Vidyapeeth), Pune, Maharashtra, India 